\title{
ALTERNATIVAS ECOEFICIENTES PARA TRATAMENTO DE EFLUENTES EM COMUNIDADES RURAIS
}

\author{
Thayze Rochele Sabei ${ }^{1}$
}

Fátima de Jesus Bassetti

\begin{abstract}
Resumo: A preocupação da sociedade com princípios ecoeficientes no tratamento de efluentes vem se destacando nos últimos anos, existem diversos tipos e sistemas para essa finalidade e que podem ser usados tanto em propriedades rurais como urbanas. O presente trabalho visa apresentar e destacar alguns desses sistemas de tratamento que se mostram como alternativas para que as comunidades humanas alcancem a sustentabilidade. A metodologia utilizada foi buscar na literatura textos científicos na área de tratamento de efluentes em propriedades rurais, para tal, foram pesquisados em bases de dados como: Google acadêmico, ScienciDirect, Periodicos da Capes, Revista Brasileira de Ciencias Ambientais, banco de teses e dissertações da USP e UTFPR. Na maioria dos trabalhos observou-se que várias técnicas estão sendo adotadas com diversas tecnologias, como banheiro seco, wetlands, escoamento superficial no solo e outros. Foi possível observar que alguns dos trabalhos estão em fase de implantação, adequação, não havendo ainda resultados concretos e necessita de mais estudos, desenvolvimento de tecnologias acessíveis, simples e eficazes para o saneamento básico associado a preservação ambiental. O resultado dessa pesquisa demonstrou que todos os sistemas tem um grau de eficiência satisfatória no que se propõe, destacando os Wetlands além de economicamente viável, a implantação da ETE por meio de zona de raízes pode agregar valor aos bens e serviços, utilizando de recursos naturais sustentáveis.
\end{abstract}

Palavras-chave: Saneamento. Tratamento de efluentes. Ecoeficiencia.

TTecnóloga Ambiental, Mestranda Ciência e Tecnologia PPGCTA/UTFPR,. E-mail: thayyzze@hotmail.com

2Prof. Dra. Engenharia QuimicaPPGCTA/UTFPR. E-mail: E-mail: bassetti@utfpr.edu.br 


\section{Introdução}

Um dos maiores problemas ambientais da população brasileira é a falta de tratamento dos esgotos domésticos urbanos. Segundo o Instituto Brasileiro de Geografia e Estatística IBGE (2010), no Brasil, 39\% da população não possui rede coletora de esgoto nem ao menos fossa séptica. Houve um significativo crescimento $(45,3 \%$ para $61,8 \%)$ da proporção de domicílios com saneamento adequado entre 1991 e 2010.

Na zona rural, o déficit é de 17,5\% para abastecimento de água é de $96 \%$ para coleta de esgoto, situação agravada porque $38 \%$ das pessoas não possuem sanitários em suas residências e cerca de 50\%fazem uso de fossas negras (BRASIL, 2003).

Atualmente, frente aos grandes problemas relacionados à falta de esgotamento sanitário, várias tecnologias estão sendo desenvolvidas e implementadas para que se possa ser implantadas como modelos viáveis para os diversos casos que carecem desses sistemas.

A situação socioeconômica brasileira faz com que sejam imprescindíveis os investimentos no desenvolvimento de tecnologias alternativas de baixo custo e boa eficiência para o tratamento das águas residuárias. Conforme BRIX (1994), uma possibilidade é a implantação de tratamento de efluentes no local onde são produzidos, utilizando os sistemas naturais na interação, o que não requer mão de obra especializada, apresenta baixo custo energético e é menos suscetível às variações nas taxas de aplicação de esgoto.

Segundo FUNASA (2010), a relação de investimento em saneamento é de aproximadamente um (1) para quatro (4), ou seja, a cada $R \$ 1,00$ investido no setor temos cerca de $R \$ 4,00$ reais economizados com saúde. O que mostra a grande importância da disposição adequada desses esgotos para a proteção da saúde pública.

Outra importante razão para tratar os esgotos diz respeito à preservação ambiental. As substâncias presentes nesses dejetos exercem ações deletérias nos corpos d'água: a matéria orgânica pode ocasionar a exaustão do oxigênio dissolvido, resultando na morte de peixes e outros organismos aquáticos, bem como no escurecimento da água e aparecimento de maus odores. Isso porque, os nutrientes acarretam uma forte "adubação" 

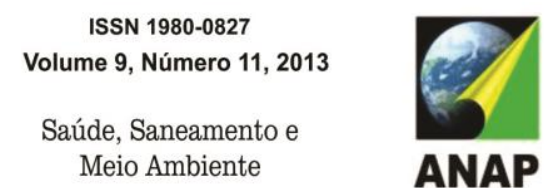

ANAP

da água, provocando o crescimento acelerado de vegetais microscópios responsáveis pelo sério desequilíbrio ecológico, além do odor e gosto desagradáveis (RODRIGUES, 2012).

Diversos trabalhos científicos vêm sendo realizados com tratamento de efluentes descentralizado como o círculo de bananeiras, fossa séptica biogestora, banheiro seco, escoamento superficial no solo e zona de raízes entre outros que estão sendo publicados em periódicos, revistas, anais de eventos e outros.

As ações técnicas direcionadas ao saneamento básico esbarram sempre em uma mesma situação, a não sustentabilidade das tecnologias implantadas, predominância de coletores públicos, com estações elevatórias, que demandam elevados gastos de implantação e operação. Situação essa decorrente da ausência de políticas públicas que promovam a disseminação de conhecimentos relacionados ao saneamento básico com uma ecoeficiência de forma interativa e participativa, por meio de uma pedagogia educacional voltada para a importância da preservação ambienta(THIOLLENT, 2005).

Segundo Almeida (2007), um projeto que seja sustentável deve seguir critérios da ecoeficiência, como: (1) Reduzir o consumo de materiais com bens e serviços; (2) Reduzir o consumo de energia com bens e serviços; (3) Reduzir a dispersão de substâncias tóxicas; (4) Intensificar a reciclagem de materiais; (5) Maximizar o uso sustentável de recursos renováveis; (6) Prolongar a durabilidade dos produtos; (7) Agregar valor aos bens e serviços.

A ecoeficiência é alcançada mediante o fornecimento de bens e serviços a preços competitivos que satisfaçam as necessidades humanas e que tragam qualidade de vida, ao mesmo tempo em que ocorre a busca da redução progressiva do impacto ambiental e do consumo de recursos ao longo do ciclo de vida até um nível, no mínimo, equivalente à capacidade de sustentação estimada da Terra (Conselho Empresarial Brasileiro para o Desenvolvimento Sustentável, 2004).

Partindo desse pressuposto, a realização desse estudo, busca levantar um aparato bibliográfico, demonstrando a importância do saneamento para a população que mora em comunidades rurais. Esse estudo é de suma importância para um futuro estudo longitudinal da aplicabilidade dos sistemas já existentes e sua eficiência. 


\section{Procedimento Metodológico}

A metodologia utilizada neste estudo consistiu no levantamento bibliográfico de textos científicos publicados em periódicos disponibilizados nas bases de dados: Google acadêmico, Periódico da Capes, Science Direct, teses e dissertações disponíveis UTFPR. Também foram consultados os periódicos: Revista Brasileira de Ciências Ambientais.

A busca foi por assunto e as palavras chave utilizadas na língua portuguesa foram: Saneamento Rural; Tratamento de Efluentes em Propriedades Rurais, círculo de bananeiras, wetlands, banheiro seco e escoamento superficial no solo. As palavras chaves utilizadas, em inglês, no sistema de busca foram: Rural Sanitation, Wastewater Treatment in Rural Properties.

Foram identificados 35 textos, dos quais 29 são artigos (revisão crítica, atualização, resultados de pesquisas de natureza empírica e experimental ou conceitual, análises e avaliações de tendências teórico-metodológicas em saneamento); 1é apresentado como opinião (opinião qualificada sobre tópico específico); 4 trabalhos de conclusão de curso de graduação (TCC); 1é nota e informações (relatos de resultados parciais ou preliminares de estudos originais ou avaliativos contendo dados e informações inéditas e relevantes para a saúde pública)

Cada texto foi submetido a uma primeira etapa de consultas com o objetivo de identificar possíveis aproximações das abordagens apresentadas com a ecoeficiência no tratamento dos efluentes. Após a consulta, 4 textos foram excluídos por não terem oferecido nenhuma contribuição ao estudo, restando, portanto, 25 trabalhos. Estes foram submetidos a uma segunda etapa de consultas feita para identificação de dados que possibilitassem a caracterização das fontes de produção a partir das variáveis: a) ano de publicação; b) periódico de publicação; c) região geográfica a que os estudos se referem; f) sujeitos estudados.

Todas as respostas obtidas nas duas etapas de consultas foram analisadas, a partir das quais se realizou a análise final com base nos referenciais teóricos citados. 


\section{Referencial Teórico}

\subsection{Banheiro seco}

O banheiro seco é uma tecnologia que tem sido aplicada em diversos países do mundo, como os Estados Unidos, Canadá, Suécia, Noruega, Nova Zelândia, Inglaterra e Austrália. Onde, basicamente se utiliza o processo de compostagem para tratar e sanitizar os dejetos humanos, reduzindo o uso de água para armazenamento, tratamento e o transporte destes resíduos. No Brasil esse sistema é conhecido desde 1999, mas ainda pouco utilizado (ALVES, 2009)

O banheiro seco é um sistema de tratamento de efluentes domésticos, sendo uma alternativa para áreas rurais, onde recursos de água são escasso, regiões muito pobres ou de baixa densidade demográfica, o abastecimento de água é precário e demais oneroso para uma determinada população (ESREY, 2000).

Para Alves (2009) e Dias (2007) o princípio destes banheiros é a não utilização de um recurso finito, a água, para o transporte dos resíduos, e sim o tratamento e o aproveitamento local destes através do processo de compostagem, onde os resíduos, ao invés de serem despejados nos solos, nos rios ou no mar, são armazenados em coletores, nos quais serão compostados a partir do aquecimento gerado por algum tipo de energia que pode ser solar, elétrica, térmica ou qualquer outra que seja acessível, disponível e capaz de gerar um aquecimento colaborando para as bactérias e fungos termófilos que, além de serem responsáveis pela decomposição, são também responsáveis por ajudar a manter a temperatura alta, necessária para a eficiência da compostagem.

Segundo Lemos (2010), os banheiros secos são alternativas promissoras para o tratamento dos resíduos sólidos provenientes da excreta humana, para o combate de doenças infecciosas e parasitárias e para a utilização racional da água.

Ainda existe uma grande dificuldade para o encontro das condições ideais necessárias para que o processo ocorra. É possível perceber que há uma carência, na literatura brasileira, de informações sobre compostagem em banheiros secos. Estas informações são extremamente importantes, visto que os valores ideais para os parâmetros de temperatura, umidade, $\mathrm{pH}$ e taxa de oxigênio para compostagens em 
banheiros secos se diferem dos valores de compostagens de resíduos de outra procedência.

\subsection{Escoamento Superficial no Solo}

Este tipo de tratamento, apesar de seu grande potencial e vantagens comparativas aos outros métodos depurativos, tem sido pouco utilizado no Brasil. Uma possível explicação para esta conduta pode ser a baixa difusão desta tecnologia no meio especializado. Deste modo, torna-se de grande importância o aumento da disseminação do conhecimento sobre tal técnica, objetivando-se a sua maior aplicação. (TONETTI, 2005).

O escoamento superficial é um método de tratamento que consiste na disposição do efluente líquido na parte superior de terrenos planos construídos que tenham uma pequena declividade e baixa permeabilidade. $O$ efluente percorre por gravidade todo 0 terreno, que é recoberto por uma vegetação. Uma pequena parcela de seu fluxo é perdida por evapotranspiração e a maior parte é coletada na base do declive. É um sistema que é mais indicado para solos com baixa permeabilidade e por isso a percolação pode ser insignificante (TONETTI et al, 2009).

Segundo Chernicharo, (2005) o processo de depuração dá-se à medida que o efluente escoa no terreno recoberto pela vegetação, onde os sólidos em suspensão são "filtrados" e a matéria orgânica é oxidada pelos microrganismos que se estabelecem na cobertura das plantas e no solo.

Para as áreas rurais este sistema trás como grande beneficio, além do adequado tratamento dos esgotos, a possibilidade geração de uma água de reuso, que pode ser empregada no cultivo de diversos produtos. Outro ponto a ser destacado seria a grande quantidade de biomassa produzida, aplicável na alimentação de animais ou no enriquecimento de solo agrícola.

\subsection{Fossa séptica biogestoras}


O sistema de fossa biodigestora contribui para a viabilização do tratamento de esgoto doméstico e consequente produção de efluentes desinfetados. Consiste em um tratamento biológico do esgoto por ação de digestão fermentativa.

O sistema desenvolvido pela EMBRAPA (Empresa Brasileira de Pesquisa em Agropecuária) denomina-se Fossa Séptica Biodigestora, para substituição de fossas negras existentes na zona rural e produção de adubo orgânico. É composto por 3 caixas de cimento amianto, interligadas por tubulação de PVC, nos quais o esgoto (somente águas negras) permanece por um mês, sendo posteriormente aplicado no solo como adubo orgânico. Necessita de uso de esterco bovino para ativar o processo e deve haver a retirada (manuseio) do lodo formado.

A fossa séptica nada mais é do que um tanque enterrado, que recebe o esgoto. Ele retém a parte sólida e inicia o processo de purificação da parte líquida, o qual é concluído através da filtração no solo (BRASIL, 2001). Essas fossas sépticas são fundamentais no combate a doenças, verminoses e endemias (como a cólera), pois evitam o lançamento dos dejetos humanos diretamente nos córregos, rios, lagos ou na superfície do solo. O seu uso é essencial para a melhoria das condições de higiene das populações rurais, pelo seu baixo custo de instalação e seu simples modo de manuseio (Brasil, 2001).

Segundo Chernicharo (1997), esse método tem baixa eficiência na remoção de DQO, nutrientes e patógenos, mas segundo BRASIL (2001) a fossa séptica biodigestora é capaz de produzir adubo orgânico totalmente isento de microorganismos patogênicos para o homem como bactérias, vírus e ovos de vermes, onde mostram estudos fitos com o uso desse adubo em graviola e gerou ótimos resultados.

\subsection{Wetlands}

Uma solução apropriada para localidades do meio rural é o sistema de Tratamento de Esgoto Sanitário por Zona de Raízes. Esse sistema tem base em solos filtrantes e, é uma tecnologia auto sustentável, que pode ser utilizada de forma a atender pequenas comunidades, escola e residência unifamiliares, ocupa pequeno espaço na área externa da residência, e ainda pode ser integrado de forma não agressiva ao ambiente. (CETEC, 1985).

Os primeiros estudos com sistema de zona de raízes ou também conhecido por Wetlands construídos de fluxo vertical, foram realizados na década de 70 na Alemanha, e eram 
denominados inicialmente como Max Planck Institut Process, e a concepção de tratamento é análoga aos filtros de areia. $O$ esgoto precisa passar antes pela fossa séptica para depois ser lançado por meio de tubulações perfuradas na área plantada do filtro, ou seja, na zona de raízes plantada em cima de um filtro físico composto por um material de suporte como cascalho ou pedra britada e areia grossa (VAN KAICK, 2002).

A utilização de espécies vegetais no tratamento de esgoto representa uma tecnologia emergente que está se revelando como uma alternativa, eficiente e de baixo custo, aos sistemas convencionais (PARKINSON; SIQUEIRA; CAMPOS, 2004).

Van Kaick (2002) descreve a ETE por Zona de raízes da seguinte forma: o sistema passa pela fossa séptica e caixa de gordura, depois seguem por meio de tubulações para a estação de raízes. Sobre um filtro físico são plantadas as plantas que formam zona de raízes, o filtro deve ser estruturado por uma camada de brita $n^{\circ} 2$ ou conchas, de $50 \mathrm{~cm}$ de profundidade. Após esta camada de brita encontra-se outra camada do filtro, composta de areia que ocupa o espaço de $40 \mathrm{~cm}$ de altura entre o fundo do filtro e a camada de brita. E ao fundo ficam as tubulações que captam o efluente tratado, onde o efluente sai já tratado fora da estação

Esses tipos se sistemas são bastante apreciados, pois tem um potencial paisagístico muito bonito, que é oferecido pelas plantas, quando florescem e se integram de forma agradável seja em um espaço residencial rural, em empresas, escolas ou em qualquer outro lugar onde sejam aplicados.

\subsection{Círculo de bananeira}

O círculo de bananeira é de fácil construção e manejo, sendo um elemento fundamental na habitação urbana ou rural por cumprir mais de uma função importante: tratar a água localmente, compostar resíduos orgânicos e produzir alimentos.

Silveira, Lima e Pereira (2002) sugerem outras formas de tratamento de efluentes como o círculo de bananeiras (após passagem pela fossa séptica), processo de filtragem utilizando brita, areia e terra, outros utilizando materiais porosos e plantas aquáticas, processos que utilizam a biotecnologia para desinfecção. Há processos que reciclam o composto sólido resultante do processo de tratamento, destinando-o a compostagem, tornando-o um condicionante de solo para a agricultura. As bananeiras se adaptam bem a solos úmidos e 

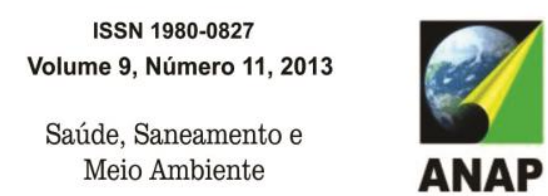

ANAP

ricos em matéria orgânica. Também podem ser plantados lírios e mamoeiros. Sua principal manutenção é a colheita dos frutos e evitar crescimento excessivo de vegetação no local.

De acordo com Martinetti et al (2009), as bananeiras evapotranspiram uma quantidade enorme de água, de acordo com a estação do ano, variedade, clima local, etc. Outras variedades podem ser plantadas no círculo para aproveitar as diferentes condições de umidade, insolação e de estrutura: espécies de sombreado podem ficar na parte interna do círculo, espécies secas do lado de fora, bem como vinhas trepadeiras "escalando" as bananeiras ou uma treliça eventualmente colocada ao centro. Ao receber água cinza normalmente rica em nutrientes compostos por restos de alimentos (pia da cozinha), terra, poeira e suor (tanque de lavar roupa e chuveiro), além de outros restos orgânicos da casa (papel, e restos de cozinha), as plantas crescem com mais vigor, produzindo frutos muito saudáveis.

Como todo sistema vivo, é importante levar em conta que a maioria absoluta dos detergentes, sabões em pó e sabonetes de banho, e produtos de limpeza doméstico contém uma infindável quantidade de contaminantes químicos que prejudicam o crescimento, e de fato a vida de espécies vegetais e animais. Martinetti et al (2009).

\subsection{Produção de biogás}

A produção do biogás representa uma melhoria global no rendimento do processo de tratamento de efluentes. Onde, por intermédio da fermentação anaeróbica que, além da capacidade de despoluir, permite valorizar um produto energético, o biogás, e ainda obter um fertilizante, cuja disponibilidade contribui para uma rápida amortização dos custos da tecnologia instalada (ANDRADE, 2002).

Um dos sistemas de obtenção do biogás mais conhecidos é o biodigestor para aplicação rural, existindo grande número de unidades instaladas, principalmente nos países originários dos modelos mais difundidos, Índia (com aproximadamente 300 mil) e a China (com mais de 8 milhões).

Segundo Pecora (2006), existem duas situações possíveis para o aproveitamento do biogás. A primeira consiste na queima direta (aquecedores, esquentadores, fogões, caldeiras). 

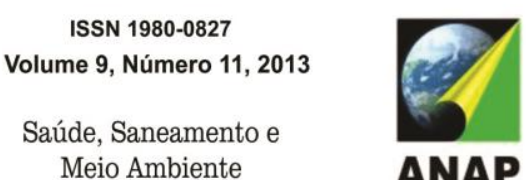

ANAP

A segunda diz respeito à conversão de biogás em eletricidade. Isto significa que o biogás permite a produção de energia elétrica e térmica.

Um sistema de geração de energia a partir do biogás possui 3 componentes básicos: a captação do gás, o processamento e conversão do gás, que promove a limpeza (remoção de partículas em suspensão e outros contaminantes) do gás e o converte em eletricidade e o equipamento de interconexão que entrega a eletricidade, a partir da geração, ao usuário final. (COSTA et al., 2001).

\section{Resultados e Discussão}

Segundo MARTINETTI et al (2009), de acordo com a dimensão política e da sustentabilidade, a participação das pessoas no processo de tomada de decisão do sistema de tratamento de esgoto, é de grande importância pois dessa maneira as decisões ficam claras e de maneira consciente. É um processo que deve ser trabalhado e incentivado.

Os banheiros secos são uma das alternativas promissoras no tratamento dos excretas humanos, para o combate de doenças infecciosas e parasitárias e para a utilização racional da água.Para ações de capacitação é importante ter informações claras como: os parâmetros de temperatura e tempo de compostagem, bem como umidade, $\mathrm{pH}$ e taxa de oxigênio para garantir a higienização nas compostagens em banheiros secos.

O sistema de tratamento por escoamento superficial segundo Tonetti(2009) é uma tecnologia viável, possuindo parâmetros construtivos e operacionais bastantesimplificados, permitindo assim, sugeri-lo como uma alternativa ao tratamento de esgotos das pequenas comunidades. Este sistema traz como grande benefício, além do adequado tratamento dos esgotos, a possibilidade de geração de uma água de reuso, que pode ser empregada no cultivo de diversos produtos. Outro ponto a ser destacado seria a grande quantidade de biomassa produzida, aplicável na alimentação de animais ou no enriquecimento de solo agrícola.

Segundo os autores, Alves (2000) e Reichert (2005), o sistema de tratamento de efluentes onde o produto final é o biogás tem se mostrado eficiente tanto em questão de tratamento do efluente como na utilização do produto final. Além de aproveitar o biogás produzido no biodigestor também pode ser utilizado o biofertilizante que é a sobra dos 
dejetos que fica no biodigestor. A produção de energia elétrica através do uso de biodigestores em propriedades rurais é muito promissora, pois, além de ser uma fonte de receita é uma atividade ecologicamente correta, contribuindo para a vida de toda sociedade.

Para MAIER (2007) e van Kaick (2002) as estações de tratamento de esgotos por meio de zonas de raízes são eficientes na redução dos poluentes microbiológicos, físicoquímicos e matéria orgânica, ele complementa a lógica das edificações sustentáveis. Sendo esta, uma alternativa viável para redução da poluição hídrica do meio rural visto que, se trata de tecnologia barata e de simples adoção, podendo ser denominada como uma tecnologia social.

$\mathrm{Na}$ Tabela 01 está apresentada um panorama das alternativas de tratamento de efluentes mais utilizadas em comunidades rurais, com algumas características e eficiência.

Tabela 01. Relação de trabalhos que apresentam alternativas de tratamento de efluentes em comunidades rurais.

\begin{tabular}{|c|c|c|c|}
\hline Autor (es) & Alternativas & Características & Eficiência \\
\hline $\begin{array}{l}\text { Alves, (2009). } \\
\text { Andrade, } \\
\text { (2003). } \\
\text { Martinetti, et } \\
\text { al, (2009). } \\
\text { Lemos, } \\
\text { (2010). } \\
\text { Uff, (2008). }\end{array}$ & $\begin{array}{l}\text { Banheiro } \\
\text { Seco }\end{array}$ & $\begin{array}{l}\text { Consiste de duas unidades } \\
\text { básicas: um local para sentar e } \\
\text { outro para armazenar as } \\
\text { excretas, sendo este o local } \\
\text { onde ocorre todo o processo de } \\
\text { degradação. Um tubo de } \\
\text { ventilação é necessário, à } \\
\text { medida que colabora para a } \\
\text { aeração no interior do banheiro } \\
\text { e impede o surgimento de } \\
\text { odores. }\end{array}$ & $\begin{array}{l}\text {-Fonte de fertilizantes. } \\
\text { - Economia de água. } \\
\text { - Tratamento eficiente } \\
\text { alternativo e ecológico. } \\
\text { - Tecnologia simples. } \\
\text { - requer educação em } \\
\text { seu uso. } \\
\text { - requer aceitação } \\
\text { cultural. }\end{array}$ \\
\hline $\begin{array}{l}\text { Tonetti, } \\
\text { (2009). } \\
\text { Chernicharo, } \\
\text { (2005) }\end{array}$ & $\begin{array}{l}\text { Escoamento } \\
\text { Superficial }\end{array}$ & 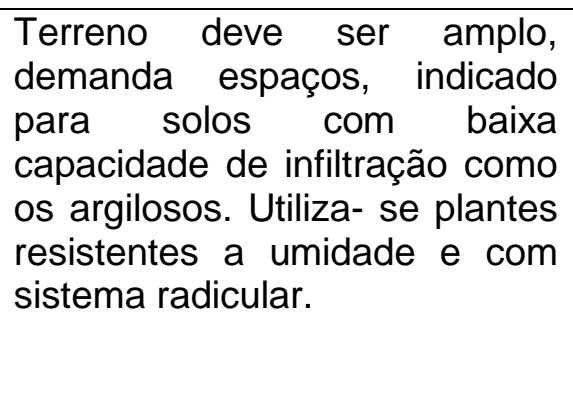 & 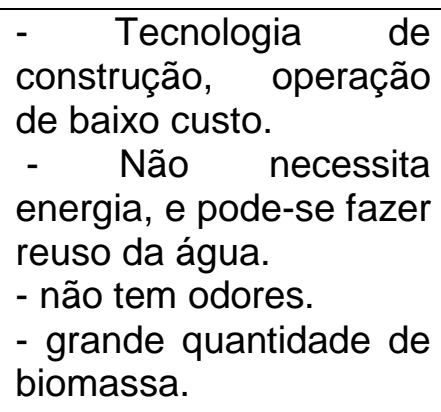 \\
\hline $\begin{array}{l}\text { Brasil, (2001). } \\
\text { Chernicharo, } \\
\text { (1997). } \\
\text { Peres et al, } \\
\text { (2010). }\end{array}$ & $\begin{array}{l}\text { Fossa } \\
\text { Séptica }\end{array}$ & $\begin{array}{l}\text { Promove tratamento eficiente } \\
\text { de desejos humanos, sistema } \\
\text { comum de buracos } \\
\text { compactados com caixas de } \\
\text { fibra alimentado diretamente }\end{array}$ & \begin{tabular}{lr}
\multicolumn{2}{l}{ - Tecnologia simples de } \\
fácil instalação \\
manutenção. \\
- melhoria dos \\
parâmetros $\quad$ que
\end{tabular} \\
\hline
\end{tabular}




\begin{tabular}{|c|c|c|c|}
\hline $\begin{array}{l}\text { Faustino, } \\
\text { (2010). }\end{array}$ & & dos vasos sanitários. & $\begin{array}{ll}\text { caracterizam } & \text { os } \\
\text { recursos hídricos. } & \end{array}$ \\
\hline $\begin{array}{l}\text { Pecora, } \\
\text { (2006) } \\
\text { Reichert, } \\
\text { (2005) } \\
\text { Andrade et al, } \\
\text { (2002). } \\
\text { Alves, (2000). } \\
\end{array}$ & $\begin{array}{l}\text { Produção de } \\
\text { Biogás }\end{array}$ & $\begin{array}{l}\text { Tratamento eficiente para } \\
\text { despoluir e, valorizar o produto } \\
\text { final, o biogás, considerado } \\
\text { energético e ainda obter } \\
\text { fertilizante. }\end{array}$ & $\begin{array}{l}\text { - Permite a produção de } \\
\text { energia térmica } \\
\text { elétrica. } \\
\text {-tem custo elevado } \\
\text { devido a equipamentos } \\
\text { necessários para } \\
\text { instalação } \\
\text { aproveitamento } \\
\text { mesmo. }\end{array}$ \\
\hline $\begin{array}{l}\text { Martinetti et al, } \\
(2007) \\
\text { Silveira et al, } \\
\text { (2002). }\end{array}$ & $\begin{array}{l}\text { Círculo de } \\
\text { bananeiras }\end{array}$ & $\begin{array}{l}\text { Tem esse nome devido as } \\
\text { bananeirasevapo- } \\
\text { transpiraremuma quantidade } \\
\text { enorme de água. Outras } \\
\text { variedades podem rer } \\
\text { plantadas no círculo para } \\
\text { aproveitar as diferentes } \\
\text { condições de umidade, } \\
\text { insolação e de estrutura. Ao } \\
\text { receber água r cinza } \\
\text { normalmente rica em } \\
\text { nutrientes, as plantas crescem } \\
\text { com mais vigor, produzindo } \\
\text { frutos. }\end{array}$ & $\begin{array}{l}\text { Promove a recarga do } \\
\text { lençol freático } \\
\text { - Diminui o consumo de } \\
\text { água tratada (para } \\
\text { irrigação) } \\
\text { - Mantém os nutrientes } \\
\text { no local promovendo o } \\
\text { crescimento das plantas } \\
\text { e árvores. } \\
\text { - Diminui o volume de } \\
\text { esgoto } \\
\text { consequentemente o } \\
\text { impacto em fossas e na } \\
\text { rede de tratamento. } \\
\text {-Causa menor demanda } \\
\text { de energia e uso de } \\
\text { químicos }\end{array}$ \\
\hline $\begin{array}{l}\text { Santos, et al, } \\
\text { (2011). } \\
\text { Van Kaick, } \\
\text { (2002). } \\
\text { Sipinski, et al, } \\
\text { (2000) } \\
\text { Almeida et al, } \\
\text { (2007). } \\
\text { Maier, (2007). } \\
\text { Phillippi, et al, } \\
\text { (2006). } \\
\text { Wagner, } \\
\text { (2008). } \\
\text { Sullivan et al, } \\
\text { (2007) }\end{array}$ & Wetlands & $\begin{array}{l}\text { O sistema de tratamento de } \\
\text { esgotos por disposição no solo } \\
\text { com interação de plantas, } \\
\text { constituído por tanque séptico, } \\
\text { seguido do tratamento } \\
\text { secundário zona de raízes. } \\
\text { aseado na relação infiltração/ } \\
\text { percolação. Flexibilidade de se } \\
\text { adaptar em } \\
\text { ambientes com diferentes } \\
\text { plantas. }\end{array}$ & $\begin{array}{l}\text {-baixo custo de } \\
\text { implantação, operação } \\
\text { e manutenção. } \\
-\quad \text { eficiente para } \\
\text { tratamento de efluentes } \\
\text { domésticos. - melhoria } \\
\text { dos parâmetros que } \\
\text { caracterizam recursos } \\
\text { hídricos. } \\
\text {-não produz resíduo, } \\
\text { (lodo). }\end{array}$ \\
\hline
\end{tabular}

Continuação Tabela 01. Relação de trabalhos que apresentam alternativas de tratamento de efluentes em comunidades rurais. 


\section{Considerações finais}

Durante a pesquisa, percebe-se que muitos artigos e trabalhos na área apresentam apenas propostas e desenvolvimento de tecnologias, ou ainda estão sendo desenvolvidos, não tendo um resultado concreto.

O processo participativo para a escolha do sistema de efluentes sanitários, é muito importante e possibilita a adoção de técnica compatível com os recursos financeiros disponíveis, e os recursos naturais. Os trabalhos mostram à necessidade de se examinar as múltiplas variáveis que influenciam na execução do sistema de tratamento de efluentes sanitários residenciais, do ponto de vista das múltiplas dimensões da sustentabilidade, como a governabilidade dos recursos financeiros e conflitos interpessoais e a ecoeficiência do sistema.

Todos os sistemas mostram-se um grau de eficiência bastante relevante, podendo ser considerado tratamento eficiente, combinando o desempenho econômico, social e ambiental, reduzindo impactos e podendo utilizar a matéria - prima local.

As Estações de Tratamento de Esgotos por Zona de Raízes (ETEZR) se destacam pelo seu o baixo custo de operação, a facilidade de operação e manejo, remoção satisfatória da matéria orgânica, sólidos suspensos, nitrogênio e fósforo, considerável remoção dos patógenos além da biomassa formada poder ser utilizada para fins econômicos, através de confecção de produtos artesanais como cestos e similares, amenizando assim o problema da falta de saneamento básico em zona rural e promovendo uma melhor qualidade de vida para a população.

Estes trabalhos abrem caminhos para outras pesquisas na área, mostrando a importância do saneamento.

\section{Referencias Bibliográficas}

ABNT - Associação Brasileira de Normas Técnicas. Resíduos Sólidos- Classificação. NBR 10004. São Paulo. 1997. 63p. 
ALMEIDA, Rogério de Araújo; OLIVEIRA, Luis Fernando Coutinho; KLIEMAN, Humberto José. Eficiência de espécies vegetais na purificação de esgoto sanitário. Pesquisa Agropecuária Tropical. V37, n.1, p1-9, 2007.

ALVES, J.W.S. Diagnóstico técnico institucional da recuperação e uso energético do biogás gerado pela digestão anaeróbia de resíduos. Dissertação de Mestrado. Programa interrunidades de Pós graduação em energia (PIPGE) do Instituto de Eletrotécnica e Energia (IEE) da Universidade de São Paulo. 142 p. São Paulo, 2000

ALVES, B. S. Q. Banheiro Seco:Análise da Eficiência de Protótipos em Funcionamento. Florianópolis - SC. 2009. Trabalho de Conclusão de Curso. Departamento de Ciencias Biológicas. Universidade Federal de Santa Catarina

ANDRADE, M. A. N. Biodigestores rurais no contexto da atual crise de energia elétrica brasileira e na perspectiva da sustentabilidade ambiental. Procedings ofthe 4th Encontro de Energia no Meio Rural, 2002.

BABATUNDE, A.O, ZHAO, M. O'NOILL, B.O'SULLIVAN. Centre for Water Resources research School of Arquiteture, Landscape and Civil Engineering University College, Dublin, Belfield, Dublin Ireland. Magazine Enviromentol International, 2007. 116-126

BRASIL. EBRAPA. Fossa Séptica Biogestora. São Carlos, 2001.http://www.municipais/default_indicadores_sociais_municipais.shtm Acesso: 22/05/2013

BRASIL. Ministério da Saúde. Portaria n. 2914, de 12 de dezembro de 2011. Dispõe sobre os procedimentos de controle e de vigilância da qualidade da água para consumo humano e seu padrão de potabilidade. Diário da União, Brasília, dez/2011

Conselho Empresarial Brasileiro para o Desenvolvimento Sustentável. (CEBDS, 2004) Ecoeficiência. http://www.cebds. org.br, Acesso em: 28 Maio 2013.

CETEC - Fundação Centro Tecnológico de Minas Gerais. Prática de Implantação de Disseminação de Tecnologias Apropriadas ao meio Rural - Projeto Juramento. Belo Horizonte, p. 191, 1985.

CHERNICHARO, C. Reatores Anaeróbios. 1a edição. Belo Horizonte: UFMG, 1997. 245p. 245 p. 
ESREY S.A. RethinkingSanitation: PanaceaorPandora's Box. In: Chorus I, Ringelband U, Schlag G e Schmoll O (eds), Water, Sanitationand Health, InternationalWaterAssociation, London. 2000.

FAUSTINO, Adriana Soares. Estudos físico-químicos do efluente produzido por fossa séptica biodigestoraeo impacto do seu uso no solo. São Carlos, 2007.

FUNDAÇÃO NACIONAL DE SAÚDE - FUNASA. Manual de saneamento. Brasília: Ministério da Saúde, 2010.

INSTITUTO BRASILEIRO DE GEOGRÁFIA E ESTATÍSTICA - IBGE. Censo 2010 http://www.ibge.gov.br/home/estatistica/população/censo2010/indicadores_sociais.Acessad o 28/05/2013

LEMES, João LVB Tratamento de esgoto por meio de zona de raízes em comunidade rural. Revista Acadêmica Ciências Agrárias Ambientais, Curitiba, v.6, n.2, 0.169-179, 2008. http://xa.yimg.com/kg/groups/28797747/name/zona+raizes-descr.pdf.

Acessado em 28/05/2013

LEMOS, Sofia; Estudo de Banheiro Seco de Capacitação para sua Implantação e Aproveitamento dos Subprodutos Gerados. Trabalho de Conclusão do curso de Graduação em Engenharia Sanitária e Ambiental. 2010. Universidade Federal Santa Catarina

MAIER, Clamarion. Qualidade de águas superficiais e Tratamento de águas residuárias por meio de zonas de raízes em propriedades de Agricultores familiares. 2007. Tese de Doutorado. Dissertação (Mestrado em ciências do solo), Universidade Federal de Santa Maria, Santa Maria- RS.

MARTINETTI, Thaís; SHIMBO, Ioshiaqui; TEIXEIRA, Bernardo AN. Análise de alternativas mais sustentáveis para tratamento local de efluentes sanitários residenciais.IV Encontro Nacional E II Encontro Latino-Americano Sobre Edificações e Comunidades Sustentáveis, 2007.

MARTINETTI, Thaís H.; SHIMBO, Ioshiaqui; TEIXEIRA, Bernardo AN. Pesquisa-ação participativa para escolha de sistema de tratamento de efluentes sanitários. residenciais mais sustentáveis. caso: assentamento rural sepé-tiaraju, serra azul, sp. Ambiente Construído, V.9, n. p 43-55 2009.

PARKINSON, J.N,; SIQUEIRA, E.Q,; CAMPOS, L.C. Tratamento de esgotos domésticos de pequenas comunidades utilizando áreas alagadas construídas (AACs). Revista Intercursos, v. 3, n. 2, Jul/Dez, p. 135,139,2004.

PECORA, Vanessa. Implantação de uma unidade demonstrativa de geração de energia elétrica a partir do biogás de tratamento do esgoto residencial da USP-Estudo de Caso. Implantação de uma unidade demonstrativa de geração de energia elétrica a 
partir do biogás de tratamento do esgoto residencial da USP: estudo de caso, 2006.

PILZ, Silvio Edmundo; SATTLER, Miguel Aloysio. banheiros compostáveis: uma solução mais sustentável, evitando a geração de águas negras. CONGRESSO BRASILEIRO DE CIÊNCIA E TECNOLOGIA EM RESÍDUOS E DESENVOLVIMENTO SUSTENTÁVEL Costão do Santinho - Florianópolis - Santa Catarina

REICHERT, G.A. e SILVEIRA, D.A. 2005. Estudo de viabilidade da digestão anaeróbia de resíduos sólidos urbanos com geração de energia. In: $23^{\circ}$ CONGRESSO BRASILEIRO DE ENGENHARIA SANITÁRIA E AMBIENTAL, 2005, Campo Grande, Brasil.

SANTOS, R. J.; FORTES NETO, P.; BATISTA, G. T. Tratamento de efluentes por leito cultivado: Sistema parapequenas comunidades. Repositório eletrônico Ciências Agrárias, Coleção Ciências Ambientais. 2007

SILVEIRA, A.L.R.C.; LIMA,F.K.G.M.; PEREIRA,K.V.V. A sustentabilidade ambiental aplica em ecovilas no município de Teresina. Núcleo de Pesquisa em Tecnologia da Arquitetura e Urbanismo (NUTAU), Universidade Estadual de São Paulo (USP) 2002.

SIPINSKI, M. A.; VAN KAICK, T. S..Estação de tratamento de esgoto (ETE) piloto na Reserva Morro da Mina/SPVS, Antonina Paraná.Curitiba: Cad. Litoral, 3: 64p., 2000.

SEITZ, P. NaturnaheAbwasserreinigungmitPflanzensystemen. StadtundGrün, p. 494 - 497, jul. 1995. OLIVEIRA, E. M. Educação ambiental: uma possível abordagem. $2^{\circ} \mathrm{Ed}$. Brasilia, DF: IBAMA, 185p., 2000

THIOLLENT, M. Metodologia da pesquisa-ação. 14. ed. São Paulo: Cortez, 2005.

TONETTI, A. L. Método para tratamento de esgotos e produção de água de reúso: Filtro anaeróbico combinado com filtro de areia e reator de desnitrificação. Campinas, 2009. Tese deDoutorado -Faculdade de Engenharia Civil.Universidade Estadual de Campinas.

TONETTI, A. L.; CORAUCCI FILHO, B.; STEFANUTTI, R.; FIGUEIREDO, R. F.; SÃO PEDRO, C. C. O. Tratamento de esgotos de pequenas comunidades pelo método de escoamento superficial do solo. Teoria e pratica na Engenharia Civil, n.13, p,69-79 maio, 2009.

UFF, Mirian Barros Teixeira. SANITARIO SECO COMPOSTAVEL, UMA ALTERNATIVA VIAVEL DE SANEAMENTO AMBIENTAL. IV CONGRESSO NACIONAL DE EXCELÊNCIA EM GESTÃO. Niteroi - RJ, 2008 
KAICK, T.S.V. Estação de tratamento de esgoto por meio de zona de raízes: uma proposta de tecnologia apropriada para saneamento básico no litoral do Paraná. 2002. 128 f. Dissertação (Mestrado em Tecnologia) - Universidade Tecnológica Federal do Paraná, Curitiba, 2002.

VAN KAICK, T. S., MACEDO, C. X. e PRESZNHUK, R. A. O. Parasitoses intestinais como indicadores da inadequação da infra-estrutura de saneamento - estudo de caso Ilha Rasa/Paraná. In: Congresso Brasileiro de Pesquisas Ambientais e Saúde - 5 CBPAS, 2005, Santos. Anais do V CBPAS, Santos: COPEC. 